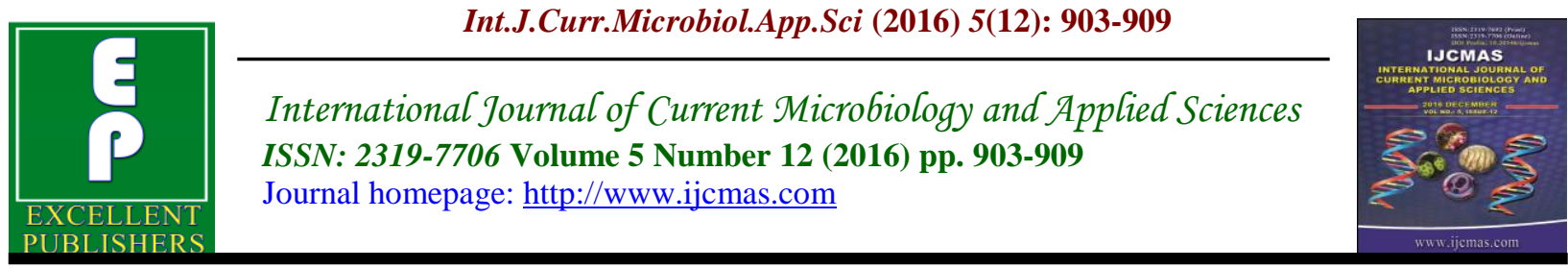

Original Research Article

http://dx.doi.org/10.20546/ijcmas.2016.512.098

\title{
Measurements of Some Asthma Markers (IgE, IFNy, IL-4 IL) by ELISA Technique and FOXP3 and IL-10 Expression in Asthmatic Patients
}

\author{
Hamadi Aabttan Al-Hilali* and Mohammed Mousa Atta \\ Department of Microbiology, College of Medicine/Al-Qadissyia University, Iraq \\ *Corresponding author:
}

\begin{tabular}{|c|c|}
\hline & A B S T R A C T \\
\hline $\begin{array}{l}\text { Asthma (IgE, } \\
\text { IFN } \gamma \text {, } \\
\text { IL-4 IL, } \\
\text { FOXP3 and IL-10) } \\
\text { titration. }\end{array}$ & \multirow{3}{*}{$\begin{array}{l}\text { This study was conducted in } 100 \text { diagnosed asthmatic patients in Hilla specialized } \\
\text { center for allergy and } 100 \text { apparently healthy control. As found there was } \\
\text { statistically significant increasing in serum IgE, IL- } 4 \text {, IFN } \gamma \text {, FOXP3 and IL-10 in } \\
\text { asthmatic patients compared to healthy controls. Measuring of (IgE, IFN } \gamma \text {, IL- } 4 \\
\text { titers, FOXP3 and IL-10 gene expression) in asthmatic patients. By taking } 3 \mathrm{ml} \text { of } \\
\text { venous blood in non heparinized tubes for separating of serum and measuring of } \\
\text { (IgE, IFN } \gamma \text { and IL-4) by ELISA technique and } 2 \mathrm{ml} \text { of venous blood in } \\
\text { heparinized tubes for IL-10 and FOXP3 gene expression. There was significant } \\
\text { increasing (P 0.001) in (IgE, IFN } \gamma \text {, IL- } 4 \text { titers and FOXP3 and IL-10 gene } \\
\text { expression compared to healthy control. There was significant increasing in } \\
\text { (IgE, IFN } \gamma \text {, IL-4 titers, FOXP3 and IL-10 gene expression ) compared to healthy } \\
\text { control. }\end{array}$} \\
\hline Article Info & \\
\hline $\begin{array}{l}\text { Accepted: } \\
\text { 20 November } 2016 \\
\text { Available Online: } \\
10 \text { December } 2016\end{array}$ & \\
\hline
\end{tabular}

\section{Introduction}

Airway allergy is a worldwide health problem, an estimated 300 million persons worldwide have asthma and about 400 million person suffer from allergic rhinitis, the prevalence of both diseases is markedly increasing (Adamko et al., 1999). Allergic reactions occur to normally harmless environmental substances known as allergen ; these reactions are acquired, predictable and rapid (Aceves et al., 2008; American Thoracic Society, 1995). Strictly, allergy is one of four forms of hypersensitivity and is called type I or (immediate) hypersensitivity, its characterized by excessive activation of certain white blood cells called mast cells and basophiles by a type of antibodies known as IgE, resulting in an extreme inflammatory response (Anderson, 2005; Aihara et al., 2004). Common allergic reactions include eczema, hives, hay fever, asthma attacks, food allergies and reaction to venom of stinging insects such as wasps and bees (Akbari et al., 2001; Asher et al., 2004). Interferons are proteins made and released by the cells of the most vertebrates in response to the presence of pathogens such as viruses, bacteria, parasites or tumor cells and they allow communication between cells to trigger the protective defenses of the immune system that eradicate pathogen or tumor cells (Ahmadi et al., 2003). IFNs belong to the large class of glycoproteins known as cytokines. Although they are 
named after their ability to "interfere" with viral replication within host cells, IFNs have other function; they activate immune cells such as natural killer cells and macrophages, they increase recognition of infection or tumor cells by up-regulating antigen presentation to $\mathrm{T}$ lymphocytes and they increase the ability of uninfected host cells to resist new infection by virus (Aihara et al., 2003). Certain host symptoms such as aching muscles and fever are related to the production of IFNs during infection, there are several single nucleotide polymorphisms (SNPs) in gene coding for IFN $\gamma$ have been reported has a specific association with number of different diseases. Also there are many different factors play important role in mechanism of asthma as IgE which is released after $\mathrm{Ag}$ sensitization and finally leading to degranulation of basophiles and mast cells ; IL-4 which is responsible for survival and maintenance of basophiles and immunomodulation of immune response from IgM towards IgE; IL-10 has contradictory effect in case of asthma, and Treg cells has immunoregulatory effect (AlZubadi, 2013). Also there is specific relationship between nasal carriage of Staphylococcus aureus and allergic rhinitis so that in this study shade light on a relationship between Staphylococcal nasal carriage with asthma exacerbation.

\section{Methods}

In a case control study, a total of 100 patients with asthma were referred to Hilla Allergy Specialized Center after they were suspected to have asthma according to their clinical manifestations, radiological changes, skin test and confirmed by allergen assay. Venous blood samples were collected from 100 patients suffering from asthma. The age of the patients are ranging from (10 - 75) years old including (40 males) and (60 females). Venous blood samples were taken from apparently healthy persons not suffering from any respiratory problems and have - ve family history to asthma, included 100 persons equal 50 males and 50 females with age range approximately matched to that of patients all control group confirmed diagnosed by radiological $\mathrm{X}$ - ray and allergen assay who give - ve results.

ASO-PCR technique was performed for detection interferon Gamma Gene Polymorphism in the blood of asthma patients samples as well as in healthy blood samples as control groups. methods were carried out according to method described by (Sarvari et al., 2011). Quantitative Reveres Transcription Real-Time PCR technique was performed for estimation of relative gene expression analysis (FOXP3 and IL-10). This technique was done according to method described by manufactured company.serological examination for titration of IFN $\gamma$, total IgE, IL-4 by using Elabscience kits (Elisa kits).

\section{Results and Discussion}

As shown in table (1), the original (unadjusted) $\mathrm{Ct}$ values of the two tested markers were used in exploring case-control differences. The mean $\mathrm{Ct}$ value for Foxp3 among cases (28.81) was significantly lower than that of healthy controls (31.89). Similarly, the mean $\mathrm{Ct}$ value for IL10 among cases (28.59) was significantly lower than that of healthy controls (30.89), Adjustment of the resulting $\mathrm{Ct}$ values was done by subtracting the resulting $\mathrm{Ct}$ value of the tested marker from that of a control marker known as "GAPDH" to remove the artefacts in measurements caused by extraneous factors unrelated to Asthma disease effect. The GADPH marker is known to be unaffected by Asthma disease, therefore it can be used as a reference marker to elicit a possible increase or 
decrease in the tested marker activity. The resulting adjusted measure is called "ratio" which is measured on a log scale.

As shown in table (2), the mean Foxp3 ratio among cases (2.83) was significantly higher than that of healthy controls $(-0.25)$. Similarly, the mean Foxp3 ratio among cases (3.06) was significantly higher than that of healthy controls (0.79).The adjusted ratio measures of the two markers were finally presented as a "fold change" measurements. The fold change gives a clear estimate of the amount of marker activation since it is measured in ordinary units rather than log units associated with "ratio" values presented earlier. The fold change results from exponentiation of a base value of 2 to the ratio value. i.e. the fold change measure of a tested marker tells exactly how many folds the activity of the tested marker is increased compared to a control marker (GADPH) known to be unaffected by the disease process.As shown in table (3), the median Foxp3 fold change among cases (6.21) was significantly higher than that of healthy controls (0.735), in our study we found statistically significant increasing of FOXP3 expression in asthmatic patients compared with healthy control and this agreed with who found the same results. And this increasing may be resulted from taking of Glucocorticoides as found by (Aceves et al., 2008) or may be as a result of the effect of immunotherapy in vaccinated asthmatic patients (discussed later in vaccination paragraph) as found by and this increasing in the FOXP3 is companied by significant increasing in the IFN $\gamma$ which is characteristically induce the expression of FOXP3 i.e IFN $\gamma$ has ability to convert CD4+CD25- Treg cells into CD4+CD25+FOXP3+ Treg cells. Similarly, the median IL-10 fold change among cases (7.905) was significantly higher than that of healthy controls (1.775), in this study also found significant increasing of IL-10 in asthmatic patients compared with control group and this agreed with other study by (American Thoracic Society, 1995) who found increased number of IL-10 mRNA positive cells in BAL and higher IL-10 secretion by macrophages have been shown in asthmatics when compared with controls, other study found that the number of IL-10 mRNA cells were slight increased in sputum samples of allergic asthmatics when compared with controls. Makela et al.,(2000) showed higher production of IL10 in induced sputum samples of asthmatics during acute exacerbation while disagreed with many studies explained significant decreasing of IL-10 in asthmatic patients compared with control groups as IL-10 is a pleotropic cytokine that has the potential to down regulate both $\mathrm{Th} 1$ and Th2 driven inflammatory processes, whether IL-10 expression is changed in asthma is uncertain, in some studies increased and in other decreased so that after these conflicting results, the findings of this study did not reveal different IL-10 levels in asthmatics over controls also between mild, moderate and severe asthmatics. There was also no effect of IL-10 level on clinical severity and this agreed with (Arzu et al., 2012).

As shown in table (4), the median serum IgE was significantly higher among cases with Asthma (27 iu/ml) compared to healthy controls $(1.65 \mathrm{iu} / \mathrm{ml})$, in our study also found that total $\operatorname{IgE}$ was statistically significant higher in asthmatic patients than healthy control group and this result matching with (Bachert et al., 2007) who reported a significant correlation between asthma and other allergic diseases with $\mathrm{IgE}$ level, also (Asher et al., 2004) found that the total serum IgE in allergic conjunctivitis was higher than that of control in addition to who reported an elevation of serum $\operatorname{IgE}$ 
level by a more than 2 - fold in allergic skin patients. Cline and Burrows, (1989) reported the highest total $\mathrm{IgE}$ levels were seen in the asthmatic patients at age group 8-14 years. But in the presented study no significant relationship of serum Total IgE levels with any age group was observed. Interestingly no association was found with either sex, however many studies have reported males to have raised $\operatorname{IgE}$ levels $(5,8)$. Similarly, the median serum IFN gamma was significantly higher among cases with Asthma (464 $\mathrm{pg} / \mathrm{ml}$ ) compared to healthy controls (147 $\mathrm{pg} / \mathrm{ml}$ ), figure 5 and this consistent with (Adamko et al., 1999) who found significant increasing in IFN $\gamma$ in asthmatic patients and disagreed with numerous researches which proved that IFN $\gamma$ decrease in case of asthma. IFN $\gamma$ known as Th1 cytokine which its releasing lead to suppression of $\mathrm{Th} 2$ cytokines which are chiefly responsible for allergic status including asthma, in this study this significant increasing of IFN $\gamma$ in asthmatic patients may be due to several explanations; it may or may not be resulted from effect of IFN $\gamma$ polymorphism as proved by, another opinion IFN $\gamma$ do not produced by Th1 cells only, there are many different cells take part in this process, also, increasing of IFN $\gamma$ may be due to presence of infections, or, increased IFN $\gamma$ in case of polymorphism may be its non functional as proved by which result that the Th2 cytokines not suppressed by this IFN $\gamma$ and remain raised. However, stated that IFN $\gamma$, but not IL-4, is correlated with the clinical severity of atopic dermatitis, and this may be related to the capacity of IFN $\gamma$ to enhance eosinophil viability and activate vascular endothelial molecules, which in turn increases infiltration by eosinophil and induces atopic dermatitis. Asthma is a complex of different difficult events in which many different factors take part in this process not only mast, basophil cells and $\operatorname{IgE}$ but another unknown factors and cells so that, we cannot fully proved mechanisms of asthma and the prophylaxis, prevention and treatment are not fully understood. In addition, the median serum IL4 was significantly higher among cases with Asthma (464 $\mathrm{pg} / \mathrm{ml})$ compared to healthy controls (147 pg/ml), figure (3-6),

Table.1 Case-control differences in FoxP3 and IL10 Ct values

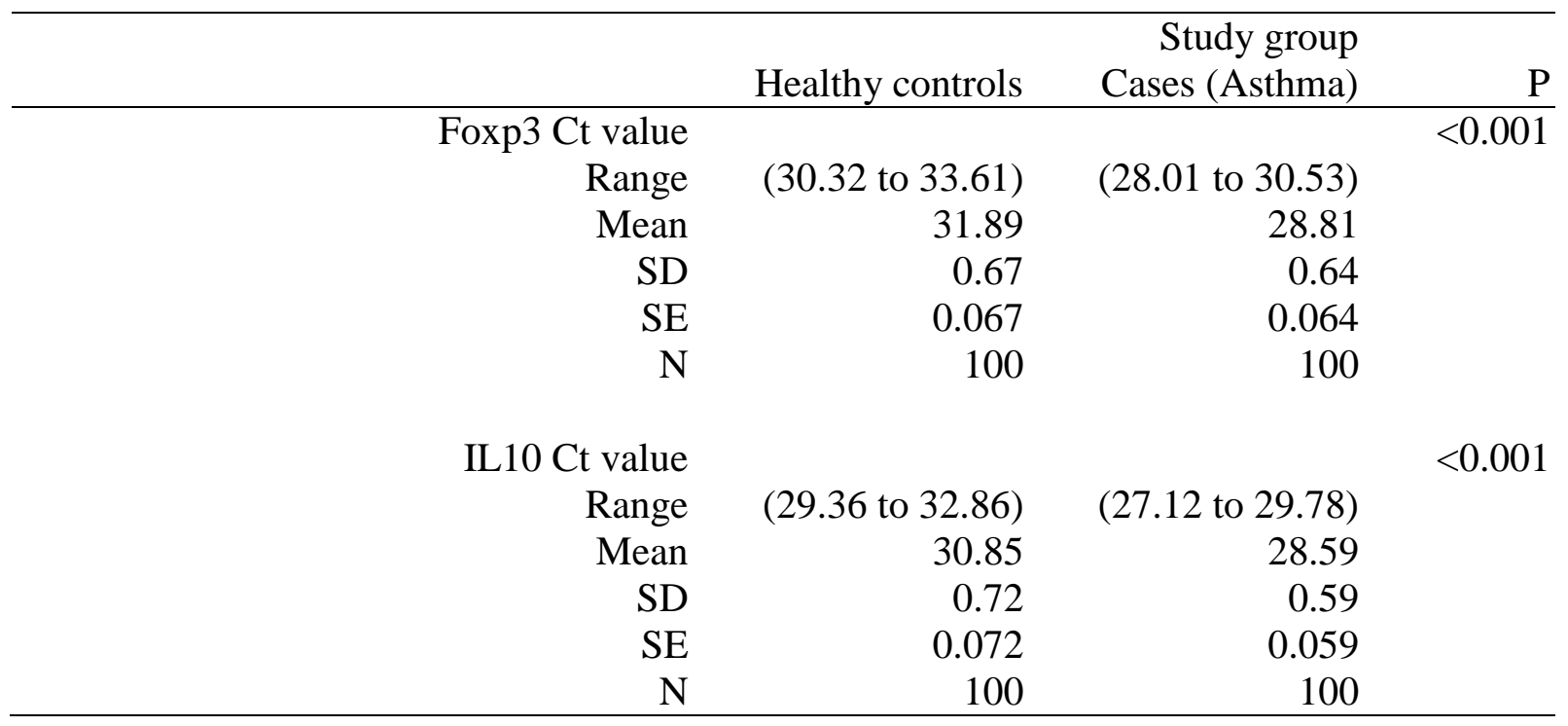


Table.2 Case-control differences in FoxP3 and IL10 adjusted Ct values (results presented as ratio values).

\begin{tabular}{|c|c|c|c|}
\hline \multicolumn{2}{|c|}{ Study group } & Cases (Asthma) & $\mathrm{P}$ \\
\hline Foxp3 ratio & & & $<0.001$ \\
\hline Range & $(-2.37$ to 2.79$)$ & (0.79 to 5.78$)$ & \\
\hline Mean & -0.25 & 2.83 & \\
\hline SD & 1.2 & 1.18 & \\
\hline SE & 0.12 & 0.118 & \\
\hline $\mathrm{N}$ & 100 & 100 & \\
\hline IL10 ratio & & & $<0.001$ \\
\hline Range & $(-1.45$ to 3.39$)$ & (1.08 to 6.04$)$ & \\
\hline Mean & 0.79 & 3.06 & \\
\hline SD & 0.97 & 1.03 & \\
\hline SE & 0.097 & 0.103 & \\
\hline $\mathrm{N}$ & 100 & 100 & \\
\hline
\end{tabular}

Table.3 Case-control differences in FoxP3 and IL10 adjusted Ct values (results presented as fold change values)

\begin{tabular}{rrrr}
\hline & & Study group & \\
& Healthy controls & Cases (Asthma) & P \\
Foxp3 fold change & & & $<0.001$ \\
Range & $(0.19$ to 6.93$)$ & $(1.73$ to 55.02$)$ & \\
Median & 0.735 & 6.21 & \\
Inter-quartile range & $(0.44$ to 1.335$)$ & $(3.84$ to 11.555$)$ & \\
Mean Rank= & 100 & 100 & \\
& 54.2 & 146.9 & \\
IL10 fold change & & & $<0.001$ \\
Range & $(0.37$ to 10.5$)$ & $(2.12$ to 65.89$)$ & \\
Median & 1.775 & 7.905 & \\
N & 105 to 2.685$)$ & $(5.2$ to 12.09$)$ & \\
Inter-quartile range & 100 & 100 & \\
Mean Rank= & 54.9 & 146.1 & \\
\hline
\end{tabular}


Table.4 Case-control differences in mean of selected serum measurements

\begin{tabular}{|c|c|c|c|}
\hline & Healthy controls & $\begin{array}{r}\text { Study group } \\
\text { Cases (Asthma) } \\
\end{array}$ & $\mathrm{P}$ \\
\hline Serum IgE conc $(\mathrm{in} / \mathrm{ml})$ & & & $<0.001$ \\
\hline Range & $(0.2$ to 3.8$)$ & (3.8 to 215.8$)$ & \\
\hline Median & 1.65 & 27 & \\
\hline Inter-quartile range & $(1.2$ to 2$)$ & (16.15 to 39.65$)$ & \\
\hline $\mathrm{N}$ & 100 & 100 & \\
\hline Mean Rank= & 50.5 & 150.5 & \\
\hline Serum IFN gamma conc (pg/ml) & & & $<0.001$ \\
\hline Range & (10 to 202$)$ & (154.5 to 1402$)$ & \\
\hline Median & 147 & 464 & \\
\hline Inter-quartile range & (119 to 163.25$)$ & $(347.25$ to 692$)$ & \\
\hline $\mathrm{N}$ & 100 & 100 & \\
\hline Mean Rank= & 50.8 & 150.2 & \\
\hline Serum IL4 conc (pg/ml) & & & $<0.001$ \\
\hline Range & (10 to 78$)$ & (304 to 2390$)$ & \\
\hline Median & 33.5 & 644.5 & \\
\hline Inter-quartile range & $(22$ to 45$)$ & $(527$ to 700$)$ & \\
\hline $\mathrm{N}$ & 100 & 100 & \\
\hline Mean Rank= & 50.5 & 150.5 & \\
\hline
\end{tabular}

In this study we found statistically significant increasing in IL-4 titer in asthmatic patients and this agreed with (Adamko et al., 1999) who found the same result and this increasing can be explained that the IL-4 is necessary for differentiation of naïve $\mathrm{CD}+\mathrm{T}$ cells within the $\mathrm{Th} 2$ subpopulation secreting IL-4, IL-5, IL-6, IL10 and IL-13 although IL-4 induce IgE synthesis and enables the immediate type of hypersensitivity reactions, IL-4 is critical in isotype switching from IgM to IgE which responsible for classic allergy and implicated in the pathophysiology of asthma, expression of VCAM-1 on endothelial cells and for inducing the differentiation of Th2 cells, production of IL-5 which is essential for the differentiation of eosinophils and transmigration across endothelium and mucus secretion (Akbari, 2001). IL-4 is of critical importance in the differentiation of Th2 cells and is therefore an "upstream" cytokine that is an attractive therapeutic target in the treatment of atopic diseases. Excessive IL-4 production by Th2 cells has been associated with elevated $\operatorname{IgE}$ production and allergy (Anderson, 2005). Our observed correlation between high titers of $\mathrm{IgE}$ and IL-4 in asthmatics is compatible with the hypothesis which explain that the maintenance of elevated IgE synthesis in these patients is at least partly IL-4 dependent (Akuthota et al., 2011).

\section{References}

Aceves, S.S. and Broide, D.H. 2008. Airway fibrosis and angiogenenesis due to eosinophil trafficking in chronic asthma. J. Exp. Med., 53(2): 894-920.

Adamko, D.J., Yost, B.L. and fryer, A.D. et al., 1999. Ovalbumin sensitization 
changes the inflammatory response to subsequent para influenza infection. Eosinophils mediate airway hyperresponssiveness, $\quad \mathrm{m}(2)$ muscuranic receptor dysfunction, and antiviral effects. J. Exp. Med., 53(2): 884-901.

Ahmadi, K.R., Lanchbury, J.S. and Reed, P. et al., 2003. Novel association suggests multiple independent QTLs within chromosome 5q21-33 region control variation in total humans IgE levels. Genes Immun., 4(4): 289-97.

Aihara, M., Dobashi, K. and Iizuka, K. et al., 2003. Comparison of effects of Y27632 and Isoprotenerol on release of cytokines from human peripheral $\mathrm{T}$ cells. Clin. Exp. Allergy, 7(12): 444475.

Aihara, M., Dobashi, K. and lizuka, K. et al., 2004. Effect of Y-27632 on release of cytokines from peripheral $\mathrm{T}$ cells in asthmatic patients and normal subjects. Clin. Exp. Allergy, 2(9): 175195.

Akbari, O., Dekruyff, R.H. and Umetsu, D.T. 2001. Pulmonary dendritic cells producing IL_10 mediate tolerance induced by respiratory exposure to antigen. Nat. Immunol., 2: 725-731.

Akdis, M. et al. 2004. Immune responses in healthy and allergic individuals are characterized by a fine balance between allergen -specific $\mathrm{T}$ regulatory 1 and $\mathrm{T}$ helper2 cells. $J$. Exp. Med., 199: 1567-1575.

Akpinarli, A., Guc, D., Kalayci, O. and Yigitbas, E. 2002. Increased interleukin-4 and decreased interferon gamma production in children with asthma: function of atopy or asthma? Asthma, 39(2): 159-65.

Akuthota, P., Xenakis, J.J. and Weller P.F. 2011. Eosinophils: Offenders or general by standers in allergic airway disease and pulmonary immunity? $J$. Innate immune., 37(1): 94-111.

Al-Zubadi, A.A. 2013. Interferon gamma gene polymorphism as predisposing factor to tuberculosis in Babylon Province. $\mathrm{pH}$ thesis.

American Thoracic Society. 1995. Standardization of spirometry. Am. $J$. Respir. Crit. Care Med., 152(3): 110736.

Anderson, H.R. 2005. Prevalence of asthma. Br. Med.J., 330:1037_8.

Arzu, D., Yalcin, B., Atil, B. and Reginald, M. 2012. IL-8, IL - 10, TGF $\beta$ and GCSF levels were increased in severe persistent allergic asthma patients with anti IgE treatment.

Asher, I., Dagli, E., Johansson, S.G., Karen, H. and Tari, H. 2004. Environmental Infl uences on Asthma and Allergy Prevention of Allergy and Allergic asthma. World Allergy Organization Project Report and Guidelines. Chem Immunol Allergy. Basel, Karger, 36101.

Bachert, C., Gevaert, P., Zhang, N., VanZele, T. and Perez-Novo, C. 2007. Role of staphylococcal superantigens in upper airway disease super-antigens and Allergens. Chem. Immunol. Allergy, 93: 214.

\section{How to cite this article:}

Hamadi Aabttan Al-Hilali and Mohammed Mousa Atta. 2016. Measurements of Some Asthma Markers (IgE, IFN $\gamma$, IL-4 IL) by ELISA Technique and FOXP3 and IL-10 Expression in Asthmatic Patients. Int.J.Curr.Microbiol.App.Sci. 5(12): 903-909.

doi: http://dx.doi.org/10.20546/ijcmas.2016.512.098 